\title{
Dried Blood Spot Tests for the Diagnosis and Therapeutic Monitoring of HIV and Viral Hepatitis B and C
}

\author{
Edouard Tuaillon ${ }^{*}$, Dramane Kania ${ }^{2}$, Amandine Pisoni ${ }^{1}$, Karine Bollore ${ }^{1}$, Fabien Taieb ${ }^{3}$, \\ Esther Nina Ontsira Ngoyi ${ }^{1}$, Roxane Schaub ${ }^{4}$, Jean-Christophe Plantier ${ }^{5}$, \\ Alain Makinson ${ }^{6}$ and Philippe Van de Perre ${ }^{1}$
}

\begin{abstract}
1 Pathogenèse et Contrôle des Infections Chroniques, INSERM U1058, Centre Hospitalier Universitaire de Montpellier, Montpellier, France, ${ }^{2}$ Centre Muraz, Bobo Dioulasso, Burkina Faso, ${ }^{3}$ Emerging Diseases Epidemiology Unit, Center for Translational Science, Institut Pasteur, Paris, France, ${ }^{4}$ CIC AG/INSERM 1424, Centre Hospitalier de Cayenne, Cayenne, France, ${ }^{5}$ Laboratoire de Virologie, Normandie Université, CHU de Rouen, Rouen, France, ${ }^{6}$ INSERM U1175/IRD UMI 233, IRD, CHU de Montpellier, Montpellier, France
\end{abstract}

Blood collected and dried on a paper card - dried blood spot (DBS) - knows a growing interest as a sampling method that can be performed outside care facilities by capillary puncture, and transported in a simple and safe manner by mail. The benefits of this method for blood collection and transport has recently led the World Health Organization to recommend DBS for HIV and hepatitis B and C diagnosis. The clinical utility of DBS sampling to improve diagnostics and care of HIV and hepatitis $\mathrm{B}$ and $\mathrm{C}$ infection in hard to reach populations, key populations and people living in low-income settings was highlighted. Literature about usefulness of DBS specimens in the therapeutic cascade of care - screening, confirmation, quantification of nucleic acids, and resistance genotyping -, was reviewed. DBS samples are suitable for testing antibodies, antigens, or nucleic acids using most laboratory methods. Good sensibility and specificity have been reported for infant HIV diagnosis and diagnosis of hepatitis B and C. The performance of HIV RNA testing on DBS to identified virological failure on antiretroviral therapy is also high but not optimal because of the dilution of dried blood in the elution buffer, reducing the analytical sensitivity, and because of the contamination by intracellular HIV DNA. Standardized protocols are needed for inter-laboratory comparisons, and manufacturers should pursue regulatory approval for in vitro diagnostics using DBS specimens. Despite these limitations, DBS sampling is a clinically relevant tool to improve access to infectious disease diagnosis worldwide.

Keywords: dried blood spot, hepatitis B, hepatitis C, HIV, diagnosis, hard-to-reach population

\section{INTRODUCTION}

The use of dried blood collected on blotting paper, - "Dried Blood Spot" (DBS) -, was developed gradually after the Second World War. The beginning of diagnosis on DBS is associated with Robert Guthrie who implemented large-scale neonatal screening for phenylketonuria in the 1960s. In the field of infectious disease diagnosis, the first references to DBS relate to syphilis, with studies 
published as early as the 1950s (Blaurock et al., 1950). The DBS sample was also used for serological surveillance or diagnosis of trypanosomiasis, hepatic amebiasis, congenital rubella, or hepatitis B (Ashkar and Ochilo, 1972; AmbroiseThomas and Meyer, 1975; Farzadegan et al., 1978; Sander and Niehaus, 1980). After these modest and historic beginnings, a progressively increasing interest for DBS was observed in the early 2000's, mainly due to the needs of therapeutic monitoring of HIV infection.

The blood can be directly deposited on the filter paper when a capillary blood collection is done with a retractable incision device, or using a pipette when peripheral venous blood is collected. The procedure for DBS collection has been detailed (Ostler et al., 2014). The capillary sampling on DBS is performed at the heel of the infant and at the level of the digital pulp in children and adults. Self-sampling is possible after a minimum training. For digital samples, the fingers innervated by the ulnar nerve (half of the 3rd finger and 4th or 5th finger) are generally preferred because less sensitive than fingers innervated by the median nerve. The size of the skin penetration depends on the size and type of lancet, and determines the amount of blood that can be collected. Standard DBS cards use pre-printed circles $12 \mathrm{~mm}$ in diameter to receive between 50 and $70 \mu \mathrm{l}$ of blood. The massage of the finger before puncture and warming of the hands in warm water, can facilitate the sampling. After puncture it is important to exert a strong intermittent pressure to maintain the bleeding and complete the blotting paper card.

\section{INDICATIONS OF DBS IN INFECTIOUS DISEASES}

Dried blood spot sampling offers an alternative to the reference samples - plasma and serum - in situations where there are no facilities or expertise to take venous whole blood specimens; or where transport of body fluids is difficult. Hence, DBS specimens collected outside of healthcare facilities can be viewed as an alternative to rapid diagnostic tests (RDT). Compared to RDT, DBS sampling has advantages and limits summarized in Table 1. By comparison with RDT one of the main limit is that diagnostic approach using DBS request a post-test visit after the sampling which is associated with a risk of loss to follow up. On the other hand, it is useful to test a large number of persons by using DBS testing in a centralized laboratory, and it is possible to confirm the infections with Western blot and molecular tests. Hence, in countries with high economic resources, DBS can be used to promote access to screening in key populations having little use of care facilities. Screening programs using DBS have been running for several years in Great Britain, targeting in particular intravenous drug users. Up to $20 \%$ of new HCV diagnoses were made using DBS in 2013 in Scottish addiction treatment centers (McLeod et al., 2014). A program of this type has been implemented by the Montpellier teaching hospital since 2013 in all addiction treatment centers located in the Languedoc Roussillon Region (Accueillir, 2014). Sex workers (Shokoohi et al., 2016), homeless people (Foroughi et al., 2017), migrants and some men who have sex with men (MSM)
TABLE 1 | Comparison of the characteristics of DBS tests and rapid diagnostic tests.

\begin{tabular}{lcc}
\hline & DBS & Rapid Tests \\
\hline Capillary blood & Yes & Yes \\
Hard to reach populations & Yes & Yes \\
Immediate result (<15 min) & No & Yes \\
Return visit request & Yes & No \\
CE-IVD, FDA, WHO prequalification & No* & Yes \\
Based on laboratory expertise & Yes & No \\
Useful for all diagnosis steps & Yes & No
\end{tabular}

${ }^{*}$ Except for HIV RNA nucleic acid tests. CE-IVD, CE-marked In Vitro Diagnostic Medical Device; FDA, Food and Drug Administration. Advantages of DBS tests are indicated in green and limits in red.

(Bogowicz et al., 2016), as well as populations living in hard to reach areas such as French Guiana (Schaub, 2017) are also key populations that can have difficult access to laboratory infectious diseases testing for which the use of DBS should be considered.

In resource-limited settings the high rates of infectious disease mortality and morbidity are, to a large extent, due to a lack of diagnostic means (Global Health Workforce Alliance and World Health Organization [WHO], 2013). Insufficient access to nearby laboratory facilities is a major concern. The lack of adequate human and financial resources - health professionals and biologists - are also noteworthy. It is estimated that threequarters of Africa's population have access to minimal health care structures in Africa, and more than $90 \%$ in Asia. By contrast, less than one-third of Africans would have access to advanced health facilities and just over 50\% in Asia (RAND Corporation, 2007. Estimating the global health impact of improved diagnostic tools for the developing world; Abou Tayoun et al., 2014).

Point of care (POC) tests - usable outside healthcare facilities - and technologies requiring minimal infrastructure (near-POC tests), constitute a major progress but will require significant investments to expand the limited range of analyzable parameters. Necessity of machines maintenance, reagents supply and quality control assurance need also to be considered in a medium and long term approach for decentralized laboratories. Good acceptability of capillary blood sampling is another advantage of DBS when compared with venepuncture (Pell et al., 2014; Almond et al., 2016). In this context, sampling on DBS considers decentralized sampling as possible, whilst carrying out the test in a well-equipped centralized clinical laboratory, without waiting for the uncertain availability of new technologies and without necessity of maintaining a cold chain for transportation (Figure 1A). Transportation and storage in field situations can have a significant effect, as shown for HIV and HCV nucleic amplifications (Monleau et al., 2010; Tuaillon et al., 2010; Manak et al., 2018), and HCV antibodies testing (Marques et al., 2012). The filter papers used can also impact on the performances of in vitro diagnosis tests. Among the DBS collection cards available Whatman 903, Munktell TNF or Ahlstrom Grade 226 have been recommended but other cards have also demonstrated good performances (Waters et al., 2007; Rottinghaus et al., 2013; Smit et al., 2014; World Health Organization [WHO], 2014; Taieb et al., 2016). DBS specimens should be considered from a 
public health perspective, for which the clinical performance of the in vitro laboratory assays is crucial. The clinical performance of a test can be analyzed as a trade-off between the intrinsic performances of the assay and its accessibility in the field. The best clinical performances are obtained in populations in whom the highest proportion of infected persons are tested and detected positive. High clinical performances may be achieved using DBS based strategies (Figure 1B). Implementation of DBS for HIV viral load is considered as one of the most medically effective immediate measures to reduce AIDS-related mortality in Africa (Phillips et al., 2015).
In addition to individual diagnosis, sampling, transport and storage simplification makes the DBS a particularly suitable tool for population studies. In France the mandatory reporting system for HIV is associated with virological surveillance by the HIV National Reference Center using dried serum spot (Lot et al., 2004). The HIV National Reference Center identifies HIV types, groups, and subtypes, and estimates incidence using a recent infection test. This surveillance system provides robust and comprehensive data on the HIV epidemic in France. Other countries, such as Germany, have also integrated DBS into their HIV surveillance system thanks to the DBS ease

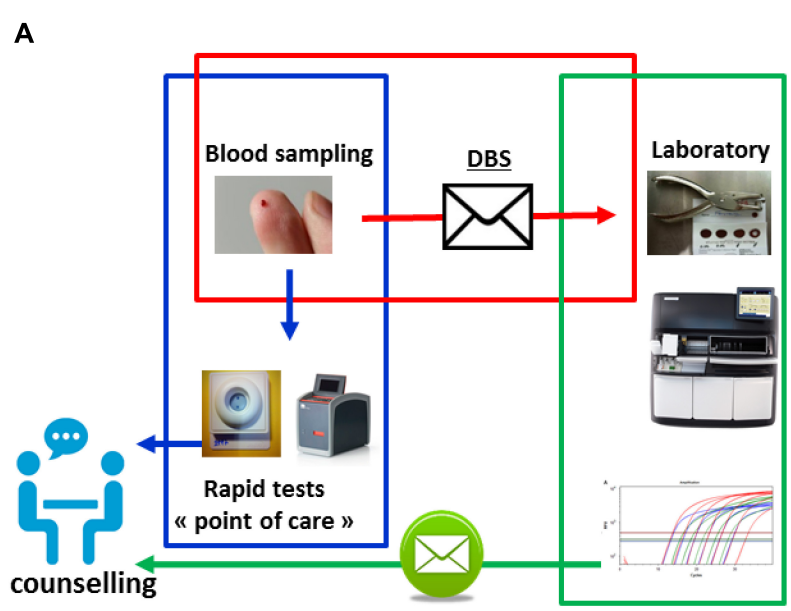

C
B

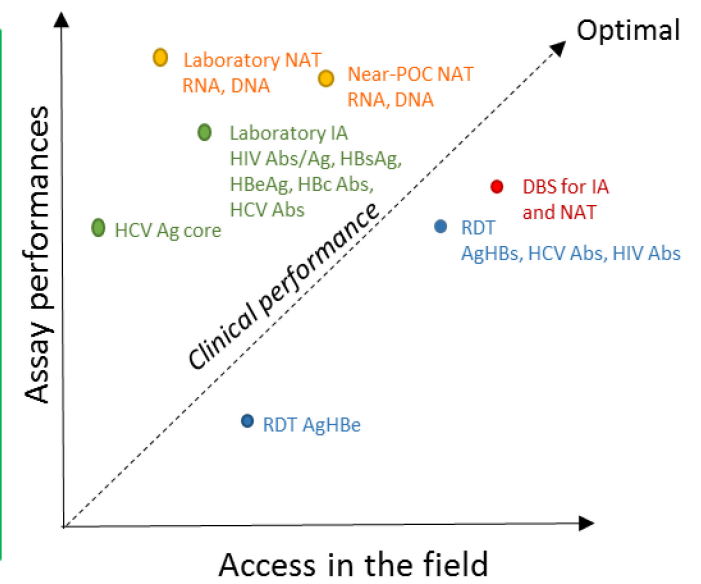

Screening anti-HIV Abs/p24 Ag: recommended by WHO for HIV surveillance anti-HCV Abs: conditional recommendation of WHO HBsAg: conditional recommendation of WHO

HIV RNA/DNA at birth in HIV exposed infants: recommended by WHO

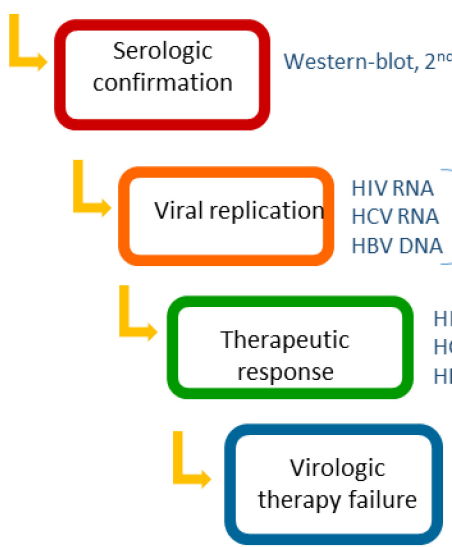

conditional recommendation of WHO IV RNA HCV RNA $\zeta$ conditional recommendation of WHO HBV DNA

HIV drug resistance genotyping: conditional recommendation of WHO Dosage of circulating drug concentrations: available evidence

FIGURE 1 | (A) Possible organization of the diagnosis and management of infections combining rapid diagnostic tests and DBS. The sampling is carried out closer to the person detected or supported. Non-laboratory RDT are carried out in the peripheral structures in parallel with the sending of the DBS to the central laboratory carrying out complementary or confirmation analyses. Results are reported as part of the post-test counseling. (B) Clinical performance of in vitro assays dedicated to HBV, HCV, and HIV infections. The figure is a schematic representation of the clinical performances considered as a trade-off between assay performances and implementation coverage. Diagnosis and monitoring strategies based on different formats of tests have different clinical performances. Each format of test is characterized by its analytical performances mainly estimated by lower limit of detection (LOD), sensibility (Se) and specificity (Sp) based on previously published studies, and its global accessibility depending on parameters such as price, infrastructure requirements, distribution network, and acceptability as evaluated based on our own experience. The clinical performance in a population can be estimate by the proportion of infected persons tested and detected positive. Abs, antibodies; Ag, antigen; HIV Abs, anti-HIV antibodies; HCV Abs, anti-HCV antibodies; IA, immuno-assay; NAT, Nucleic acid tests; Near-POC NAT, Near point of care NAT; RDT, rapid diagnostic test. (C) DBS analyses during the therapeutic cascade for HIV, HBV, and HCV infections. The sampling on DBS allows the realization of the in vitro assays which are necessary at each steps of the therapeutic cascade: screening, confirmation, measurement of the replication, analysis of the therapeutic failures. Recommendations of WHO to the usage of DBS are indicated for each step of the cascade. 
(Hofmann et al., 2017). In southern countries and areas with difficult access the DBS allows large-scale surveys to plan and monitor health programs. DBS specimens collected during Demographic and Health Surveys (DHS) are useful for estimating the prevalence of diseases, allowing reliable countrywide and regional distribution of HIV estimates (Bellan et al., 2013), but also of hepatitis B, C, and delta, as recently reported (Meda et al., 2018; Njouom et al., 2018; Tuaillon et al., 2018).

\section{DBS IN THE THERAPEUTIC CASCADE OF CARE}

Reaching and testing persons at risk of HBV, HCV, and HIV is a main challenge as part of the global effort to eliminate these infections as public health threats by 2030 (World Health Organization [WHO], 2016). Diagnosis of viral hepatitis and HIV follows a sequential strategy initiated by serological screening based on the detection of antibodies or antigens, to which succeeds a confirmation step and the therapeutic monitoring (Figure 1C). DBS analyses can be integrated into each steps of the diagnosis cascade.

\section{DBS for Screening and Serologic Confirmation of HIV and Viral Hepatitis}

Dried blood spot can be used in the initial serological screening step as an alternative to conventional assays based on venipuncture and RDT. DBS can be decentralized such as RDT, but requires a return visit for post-counseling. This second visit leads to a risk of loss to follow up (Bottero et al., 2015). The lower rate of retention in care using DBS is one of the limitations of DBS testing compared to RDT. Nevertheless, questioning health care workers about their perception of DBS testing highlights some advantages related to a diagnostic strategy requiring a second visit: (i) unlike for RDT, the person who performed the DBS does not bear the responsibility of performing the assay and of immediately notifying the diagnosis to the screened subject; (ii) in the event of a positive test, the medical team can anticipate and better organize the post-test counseling; (iii) in an approach of risk-reduction, the time between screening and the result announcement may be perceived as beneficial to raising awareness.

Dried blood spot samples can be used with standard HIV and viral hepatitis immunoassays. Automated immunoassays performed on DBS can be more efficient than RDT based on immuno-concentration, immunochromatography or agglutination methods. We reported that acute HIV infection was detected earlier on DBS using a fourth-generation HIV test (combining detection of total antibody and p24 Ag) compared to RDT (Kania et al., 2015). Suboptimal analytical sensitivity was also reported for HBsAg RDT (Scheiblauer et al., 2010). This analytical sensibility is generally insufficient to meet the minimum requirements of European regulatory authorities and WHO (Lower limit of detection (LOD) $<4 \mathrm{IU} / \mathrm{mL}$ ) (Chevaliez et al., 2014; World Health Organization [WHO], 2019). HBsAg laboratory tests have a sensitivity $<0.1 \mathrm{IU} / \mathrm{mL}$ (Tuaillon et al., 2012), suggesting that even with a dilution factor of 10 or 20 times related to the elution step, the DBS testing may have a better sensitivity than HBsAg RDT. Systematic reviews have reported 98\% sensitivity and $100 \%$ specificity for HBsAg screening on DBS compared to $88.9 \%$ sensitivity and $98.4 \%$ specificity using HBsAg RDT (Amini et al., 2017; Lange et al., 2017a). By contrast, the overall performances of RDT and DBS test dedicated to anti-HCV detection appeared very close, with 98\% sensitivity, and $99 \%$ specificity using DBS, and 98\% sensitivity and 100\% sensitivity using RDT (Lange et al., 2017a; Tang et al., 2017).

The confirmation of a positive screening test is a second and often crucial step in the cascade of care. DBS can be used for confirmation of anti-HIV and anti-HCV detection on Western blot. Results in band patterns are similar to those observed in blood and comparable performances in term of sensitivity and specificity (Tuaillon et al., 2010; Kania et al., 2013; Manak et al., 2018). However, these assays are rarely available in low incomes countries, and were generally expensive. Confirmation by genomic detection on DBS is also an effective means of confirming infections with HCV, HBV, and HIV (Tuaillon et al., 2010; Nhan et al., 2014). Nucleic acid tests on DBS are able to confirm and HIV and HCV replication since the RNA level is generally higher than the LOD in treatment naïve subjects (Smit et al., 2014; Nguyen et al., 2018), and to detect chronic active HBV infections (HBV DNA > $2000 \mathrm{IU} / \mathrm{ml}$ ). Access to a more efficient diagnostic tool in case of high clinical suspicion despite a negative result of TDR could be considered as another way of DBS use (Kania et al., 2015).

\section{DBS for HIV and Viral Hepatitis Molecular Testing to Detect Viral Replication, Therapeutic Response and Virologic Theray Failure}

One of the most obvious indications of the DBS concerns HIV, HBV, and HCV molecular tests. Testing HIV, HBV, and HCV nucleic acids is necessary for therapeutic initiation or monitoring of the therapeutic response. However, access to nucleic acid tests remains very limited in low income countries. The performances of most commercial HIV-1 RNA assays have been evaluated on DBS: Abbott RealTime, Roche Cobas, Siemens Versant, bioMérieux Nuclisens, Biocentric Generic, Cepheid GeneXpert. The Abbott test has been the most largely used assay, and can be considered as the reference for HIV viral load on DBS. The authors conclude quite consensually on the satisfactory performance of viral load on DBS (Smit et al., 2014). Nevertheless, the variability of the results must be underlined. Sensitivities ranged from less than $80 \%$ to almost $100 \%$ at the threshold of $1000 \mathrm{HIV}$ RNA/mL recommended by WHO for virological failure, and specificity from less than $60 \%$ to nearly $95 \%$ for a given test (Smit et al., 2014; World Health Organization [WHO], 2014; Taieb et al., 2016). The viral reservoir of HIV DNA induces a quantification bias when whole blood is used. The HIV DNA contained in infected cells is released into the DBS eluate. We have shown that the risk of over-quantification becomes greater over $10^{6} \mathrm{HIV}$ DNA copies per million of peripheral blood mononuclear cells (Zida et al., 2016). The use of a 
specific extraction of RNA or DNAse significantly improves the specificity (Rollins et al., 2002). At a threshold of 5000 HIV RNA copies/mL, the techniques on DBS show better performances, but this high threshold implies a deterioration of the negative predictive value for a test of therapeutic failure (World Health Organization [WHO], 2014).

The detection of nucleic acids on DBS also finds a strong clinical indication in the diagnosis of infections transmitted from mother to child. Regarding HIV diagnosis, the presence of maternal antibodies in infants makes serological tests ineffective until at least 1 year of age. Molecular diagnosis of HIV infection on DBS has been shown to be effective (Rollins et al., 2002) and is routinely used in clinical practice for this indication. DBS sampling is finally useful for specialized tests such as HIV resistance genotyping, and antiretroviral dosages (D'Avolio et al., 2010; Monleau et al., 2014). It should be noted that although the clinical relevance of HIV resistance genotyping on DBS is indisputable, it nevertheless faces the difficulty of molecular genotyping on DBS, at the threshold defining the therapeutic failure (Monleau et al., 2014).

For viral hepatitis, there are fewer data on molecular tests, but they show better clinical performance than those published for HIV. For HBV, sensitivities and specificities are estimated at $95 \%$ on average (D'Avolio et al., 2010), and the threshold for inactive hepatitis is easily reached in DBS $(<2000 \mathrm{IU} / \mathrm{mL}$, approximately equivalent to $<10,000 \mathrm{DNA}$ copies/mL). For HCV, mean sensitivities and specificities are also high and estimated $>98 \%$ (Lange et al., 2017b), which can be explained by the paucity of low HCV viremia during the natural history of this infection. Confirmation of $\mathrm{HCV}$ viremia by testing $\mathrm{HCV}$ core antigen (HCVcAg) on DBS has also recently been reported in intravenous drug users living in Africa and Asia (Mohamed et al., 2017; Nguyen et al., 2018). This method appeared highly specific and may benefit from substantial stability under prolonged storage conditions but with a lower analytical sensitivity compared to DBS HCV RNA testing (Soulier et al., 2016; Nguyen et al., 2018).

\section{SEROLOGICAL AND MOLECULAR TESTING USING DBS IN THE FIELD}

Heterogeneity in the pre-analytical procedures used for DBS specimens between laboratories influence the result and make comparisons difficult. The size of the spot, the nature of the elution buffer, the elution volume - and therefore the dilution factor -, the extraction technique, impact the performance of the tests. WHO guidelines for the implementation of HIV viral load and viral hepatitis tests stress the need for the manufacturers to provide application notes for the use of DBS, and at best to pursue regulatory approval for in vitro diagnostics using DBS specimens (World Health Organization [WHO], 2014, 2017). The bioMerieux Nuclisens and Abbott RealTime HIV-1 viral load kits have obtained regulatory approval for use on DBS. On this matrix, the detection threshold (95\% detection) is 802 copies $/ \mathrm{ml}$ for the bioMerieux test (CE-IVD) and 839 copies/ml for the
Abbott test (CE-IVD and WHO prequalification). However, a study has shown that the detection rate does not reach 95\% for viral loads between 1000 and 5000 RNA copies/mL (Viljoen et al., 2010). WHO pre-qualification of the Abbott HIV test on DBS, report a sensitivity of $76.0 \%$ and a specificity of $89.7 \%$ at the threshold of 1000 RNA copies $/ \mathrm{mL}$ (World Health Organization [WHO], 2018). Several qualitative RNA/DNA tests have regulatory approval for the perinatal diagnosis of HIV infection on DBS: the Cepheid XPERT HIV-1 QUAL test that detects HIV-1 DNA and RNA, the Abbott RealTime Qualitative test, as well as the Roche COBAS qualitative test.

For viral hepatitis B and C, no viral load test performed from DBS is currently IVD approved. The same scarcity situation must be noted for viral serology techniques, for which there is neither regulatory approval for use on DBS nor official application note from manufacturers. Despite these important limitations, DBS collection is recommended by WHO for diagnosis of HIV and viral hepatitis $\mathrm{B}$ and $\mathrm{C}$ in field settings to improve access to screening and management of populations with poor access to serum tests (Soulier et al., 2016; Taieb et al., 2018).

\section{CONCLUSION}

Capillary blood collected on blotting paper is an alternative method of sampling with many advantages compared to serum or plasma specimens. The lower analytical sensitivity of assays performed on DBS compared to serum/plasma is one of the limits of DBS, since biomarkers can be present at very low concentration during infection. However, data suggest that the analytical sensitivity of DBS is generally higher than RDT. Another limitation is the lack of commitment by manufacturers to use serological and molecular tests on DBS specimens. The pre-analytical steps of laboratory analyses performed on DBS keep a manual character, including the following steps: to punch out of the spot from each bloodsoaked circle, to transfer to the elution tube or plate, to put the tube on a laboratory shaker and let the punched DBSs gently elute for a minimum of $2 \mathrm{~h}$, to transfer the tubes to microcentrifuge to eliminate debris from the supernatants. Diagnostic tests on DBS are consequently difficult to integrate into the laboratory workflow. Hence, the tests on DBS require rigorous validation in clinical laboratories to guarantee the quality of the results. Despite these limitations, DBS is a clinically relevant tool for decentralized sampling. DBS can contribute more broadly to improve access to in vitro diagnosis in order to reach the treatment target to help end the AIDS epidemic and to eliminate viral hepatitis as a public health threat by 2030 .

\section{AUTHOR CONTRIBUTIONS}

ET, DK, AP, KB, and PV contributed to the conception and wrote the manuscript. FT, EO, RS, J-CP, and AM participated to wrote and analysis. All authors read and approved the final manuscript. 


\section{REFERENCES}

Abou Tayoun, A. N., Burchard, P. R., Malik, I., Scherer, A., and Tsongalis, G. J. (2014). Democratizing molecular diagnostics for the developing world. Am. J. Clin. Pathol. 141, 17-24. doi: 10.1309/AJCPA1L4KPXBJNPG

Accueillir (2014). accompagner, dépister les personnes à risque d'hépatites $B$ ou $C$ en Languedoc-Roussillon*. Available at: http://wwwl.chu-montpellier.fr/fr/cohep/ actualites/le-depistage-dontformations-trod/ (accessed Febuary 27, 2020).

Almond, D., Madanitsa, M., Mwapasa, V., Kalilani-Phiri, L., Webster, J., Ter Kuile, F., et al. (2016). Provider and user acceptability of intermittent screening and treatment for the control of malaria in pregnancy in Malawi. Malar. J. 15, 574. doi: 10.1186/s12936-016-1627-5

Ambroise-Thomas, P., and Meyer, H. A. (1975). Hepatic amebiasis in the Kilimanjaro region. Serodiagnosis on micro-specimens of dried blood and attempts at treatment with tinidazole (fasigyn). Acta Trop. 32, 359-364.

Amini, A., Varsaneux, O., Kelly, H., Tang, W., Chen, W., Boeras, D. I., et al. (2017). Diagnostic accuracy of tests to detect hepatitis B surface antigen: a systematic review of the literature and meta-analysis. BMC Infectious Diseases 17:698. doi: 10.1186/s12879-017-2772-3

Ashkar, T., and Ochilo, M. (1972). The application of the indirect fluorescent antibody test to samples of sera and dried blood from cattle in the Lambwe Valley, South Nyanza, Kenya. Bull. World Health Organ. 47, 769-772.

Bellan, S. E., Fiorella, K. J., Melesse, D. Y., Getz, W. M., Williams, B. G., and Dushoff, J. (2013). Extra-couple HIV transmission in sub-Saharan Africa: a mathematical modelling study of survey data. The Lancet 381, 1561-1569. doi: 10.1016/S0140-6736(12)61960-6

Blaurock, G., Rische, H., and Rohne, K. (1950). [Development of the blotting paper method in the dried blood reaction for syphilis]. Dtsch Gesundheitsw 5, 462-464.

Bogowicz, P., Moore, D., Kanters, S., Michelow, W., Robert, W., Hogg, R., et al. (2016). HIV testing behaviour and use of risk reduction strategies by HIV risk category among MSM in Vancouver. Int J STD AIDS 27, 281-287. doi: $10.1177 / 0956462415575424$

Bottero, J., Boyd, A., Gozlan, J., Carrat, F., Nau, J., Pauti, M.-D., et al. (2015). Simultaneous Human Immunodeficiency Virus-Hepatitis B-Hepatitis C Pointof-Care Tests Improve Outcomes in Linkage-to-Care: Results of a Randomized Control Trial in Persons Without Healthcare Coverage. Open Forum Infect Dis 2, ofv162. doi: 10.1093/ofid/ofv162

Chevaliez, S., Challine, D., Naija, H., Luu, T. C., Laperche, S., Nadala, L., et al. (2014). Performance of a new rapid test for the detection of hepatitis B surface antigen in various patient populations. Journal of Clinical Virology 59, 89-93. doi: 10.1016/j.jcv.2013.11.010

D’Avolio, A., Simiele, M., Siccardi, M., Baietto, L., Sciandra, M., Bonora, S., et al. (2010). HPLC-MS method for the quantification of nine anti-HIV drugs from dry plasma spot on glass filter and their long term stability in different conditions. J Pharm Biomed Anal 52, 774-780. doi: 10.1016/j.jpba.2010. 02.026

Farzadegan, H., Noori, K. H., and Ala, F. (1978). Detection of hepatitis-B surface antigen in blood and blood products dried on filter paper. Lancet 1, 362-363. doi: 10.1016/s0140-6736(78)91085-1

Foroughi, M., Moayedi-Nia, S., Shoghli, A., Bayanolhagh, S., Sedaghat, A., Mohajeri, M., et al. (2017). Prevalence of HIV, HBV and HCV among street and labour children in Tehran, Iran. Sex Transm Infect 93, 421-423. doi: 10. 1136/sextrans-2016-052557

Global Health Workforce Alliance, and World Health Organization [WHO] (2013). A Universal Truth: No Health Without a Workforce. Third Global Forum on Human Resources for Health Report*. Available at: http://www.who.int/ workforcealliance/knowledge/resources/hrhreport2013/en/ (accessed Febuary $27,2020)$.

Hofmann, A., Hauser, A., Zimmermann, R., Santos-Hövener, C., BätzingFeigenbaum, J., Wildner, S., et al. (2017). Surveillance of recent HIV infections among newly diagnosed HIV cases in Germany between 2008 and 2014. BMC Infect. Dis. 17:484. doi: 10.1186/s12879-017-2585-4

Kania, D., Bekalé, A. M., Nagot, N., Mondain, A.-M., Ottomani, L., Meda, N., et al. (2013). Combining rapid diagnostic tests and dried blood spot assays for pointof-care testing of human immunodeficiency virus, hepatitis B and hepatitis C infections in Burkina Faso, West Africa. Clinical Microbiology and Infection 19, E533-E541. doi: 10.1111/1469-0691.12292
Kania, D., Truong, T. N., Montoya, A., Nagot, N., Van de Perre, P., and Tuaillon, E. (2015). Performances of fourth generation HIV antigen/antibody assays on filter paper for detection of early HIV infections. J. Clin. Virol. 62, 92-97. doi: 10.1016/j.jcv.2014.11.005

Lange, B., Cohn, J., Roberts, T., Camp, J., Chauffour, J., Gummadi, N., et al. (2017a). Diagnostic accuracy of serological diagnosis of hepatitis C and B using dried blood spot samples (DBS): two systematic reviews and meta-analyses. BMC Infectious Diseases 17:700. doi: 10.1186/s12879-017-2777-y

Lange, B., Roberts, T., Cohn, J., Greenman, J., Camp, J., Ishizaki, A., et al. (2017b). Diagnostic accuracy of detection and quantification of HBV-DNA and HCV-RNA using dried blood spot (DBS) samples - a systematic review and meta-analysis. BMC Infectious Diseases 17:693. doi: 10.1186/s12879-0172776-Z

Lot, F., Semaille, C., Cazein, F., Barin, F., Pinget, R., Pillonel, J., et al. (2004). Preliminary results from the new HIV surveillance system in France. Euro Surveill. 9, 34-37.

Manak, M. M., Hack, H. R., Shutt, A. L., Danboise, B. A., Jagodzinski, L. L., and Peel, S. A. (2018). Stability of Human Immunodeficiency Virus Serological Markers in Samples Collected as HemaSpot and Whatman 903 Dried Blood Spots. J. Clin. Microbiol. 56, e933-e918. doi: 10.1128/JCM.00933-18

Marques, B. L. C., Brandão, C. U., Silva, E. F., Marques, V. A., Villela-Nogueira, C. A., Do Ó, K. M. R., et al. (2012). Dried blood spot samples: optimization of commercial EIAs for hepatitis $\mathrm{C}$ antibody detection and stability under different storage conditions. J. Med. Virol. 84, 1600-1607. doi: 10.1002/jmv.23379

McLeod, A., Weir, A., Aitken, C., Gunson, R., Templeton, K., Molyneaux, P., et al. (2014). Rise in testing and diagnosis associated with Scotland's Action Plan on Hepatitis C and introduction of dried blood spot testing. J Epidemiol Community Health 68, 1182-1188. doi: 10.1136/jech-2014-204451

Meda, N., Tuaillon, E., Kania, D., Tiendrebeogo, A., Pisoni, A., Zida, S., et al. (2018). Hepatitis B and C virus seroprevalence, Burkina Faso: a cross-sectional study. Bulletin of the World Health Organization 96, 750-759. doi: 10.2471/BLT.18. 208603

Mohamed, Z., Mbwambo, J., Shimakawa, Y., Poiteau, L., Chevaliez, S., Pawlotsky, J.-M., et al. (2017). Clinical utility of HCV core antigen detection and quantification using serum samples and dried blood spots in people who inject drugs in Dar-es-Salaam, Tanzania. Journal of the International AIDS Society 20, 21856. doi: 10.7448/IAS.20.1.21856

Monleau, M., Aghokeng, A. F., Eymard-Duvernay, S., Dagnra, A., Kania, D., Ngo-Giang-Huong, N., et al. (2014). Field evaluation of dried blood spots for routine HIV-1 viral load and drug resistance monitoring in patients receiving antiretroviral therapy in Africa and Asia. J. Clin. Microbiol. 52, 578-586. doi: 10.1128/JCM.02860-13

Monleau, M., Butel, C., Delaporte, E., Boillot, F., and Peeters, M. (2010). Effect of storage conditions of dried plasma and blood spots on HIV-1 RNA quantification and PCR amplification for drug resistance genotyping. J. Antimicrob. Chemother. 65, 1562-1566. doi: 10.1093/jac/dkq205

Nguyen, T. T., Lemee, V., Bollore, K., Vu, H. V., Lacombe, K., Thi, X. L. T., et al. (2018). Confirmation of HCV viremia using HCV RNA and core antigen testing on dried blood spot in HIV infected peoples who inject drugs in Vietnam. BMC Infect. Dis. 18:622. doi: 10.1186/s12879-018-3529-3

Nhan, T. X., Teissier, A., Roche, C., and Musso, D. (2014). Sensitivity of RealTime PCR Performed on Dried Sera Spotted on Filter Paper for Diagnosis of Leptospirosis. Journal of Clinical Microbiology 52, 3075-3077. doi: 10.1128/ JCM.00503-14

Njouom, R., Siffert, I., Texier, G., Lachenal, G., Tejiokem, M. C., Pépin, J., et al. (2018). The burden of hepatitis $C$ virus in Cameroon: Spatial epidemiology and historical perspective. Journal of Viral Hepatitis 25, 959-968. doi: 10.1111/jvh. 12894

Ostler, M. W., Porter, J. H., and Buxton, O. M. (2014). Dried blood spot collection of health biomarkers to maximize participation in population studies. J Vis Exp 83, e50973. doi: 10.3791/50973

Pell, C., Meñaca, A., Chatio, S., Hodgson, A., Tagbor, H., and Pool, R. (2014). The acceptability of intermittent screening and treatment versus intermittent preventive treatment during pregnancy: results from a qualitative study in Northern Ghana. Malar. J. 13, 432. doi: 10.1186/1475-2875-13-432

Phillips, A., Shroufi, A., Vojnov, L., Cohn, J., Roberts, T., Ellman, T., et al. (2015). Sustainable HIV treatment in Africa through viral-load-informed differentiated care. Nature 528, S68-S76. doi: 10.1038/nature16046 
RAND Corporation (2007). Estimating the global health impact of improved diagnostic tools for the developing world. Santa Monica, CA: RAND Corporation.

Rollins, N. C., Dedicoat, M., Danaviah, S., Page, T., Bishop, K., Kleinschmidt, I., et al. (2002). Prevalence, incidence, and mother-to-child transmission of HIV-1 in rural South Africa. Lancet 360, 389. doi: 10.1016/s0140-6736(02)09599-5

Rottinghaus, E., Bile, E., Modukanele, M., Maruping, M., Mine, M., Nkengasong, J., et al. (2013). Comparison of Ahlstrom grade 226, Munktell TFN, and Whatman 903 filter papers for dried blood spot specimen collection and subsequent HIV1 load and drug resistance genotyping analysis. J. Clin. Microbiol. 51, 55-60. doi: 10.1128/JCM.02002-12

Sander, J., and Niehaus, C. (1980). [Rubella screening using the haemolysis-in-gel test from dried newborn blood on filter paper (author's transl)]. Dtsch. Med. Wochenschr. 105, 827-829. doi: 10.1055/s-2008-1070762

Schaub, R. (2017). Hepatitis Band C in the migrant and transboundary communities of the Maroni River: the MaHevi research project*.

Scheiblauer, H., El-Nageh, M., Diaz, S., Nick, S., Zeichhardt, H., Grunert, H.-P., et al. (2010). Performance evaluation of 70 hepatitis B virus (HBV) surface antigen (HBsAg) assays from around the world by a geographically diverse panel with an array of HBV genotypes and HBsAg subtypes. Vox Sang. 98, 403-414. doi: 10.1111/j.1423-0410.2009.01272.x

Shokoohi, M., Karamouzian, M., Khajekazemi, R., Osooli, M., Sharifi, H., Haghdoost, A. A., et al. (2016). Correlates of HIV Testing among Female Sex Workers in Iran: Findings of a National Bio-Behavioural Surveillance Survey. PLoS ONE 11:e0147587. doi: 10.1371/journal.pone.0147587

Smit, P. W., Sollis, K. A., Fiscus, S., Ford, N., Vitoria, M., Essajee, S., et al. (2014). Systematic review of the use of dried blood spots for monitoring HIV viral load and for early infant diagnosis. PLoS ONE 9:e86461. doi: 10.1371/journal.pone. 0086461

Soulier, A., Poiteau, L., Rosa, I., Hézode, C., Roudot-Thoraval, F., Pawlotsky, J.-M., et al. (2016). Dried Blood Spots: A Tool to Ensure Broad Access to Hepatitis C Screening, Diagnosis, and Treatment Monitoring. J Infect Dis. 213, 1087-1095. doi: 10.1093/infdis/jiv423

Taieb, F., Tram, T. H., Ho, H. T., Pham, V. A., Nguyen, L., Pham, B. H., et al. (2016). Evaluation of Two Techniques for Viral Load Monitoring Using Dried Blood Spot in Routine Practice in Vietnam (French National Agency for AIDS and Hepatitis Research 12338). Open Forum Infect Dis 3, ofw142. doi: 10.1093/ofid/ ofw142

Taieb, F., Tran Hong, T., Ho, H. T., Nguyen Thanh, B., Pham Phuong, T., Viet Ta, D., et al. (2018). First field evaluation of the optimized CE marked Abbott protocol for HIV RNA testing on dried blood spot in a routine clinical setting in Vietnam. PLoS ONE 13:e0191920. doi: 10.1371/journal.pone.0191920

Tang, W., Chen, W., Amini, A., Boeras, D., Falconer, J., Kelly, H., et al. (2017). Diagnostic accuracy of tests to detect Hepatitis C antibody: a meta-analysis and review of the literature. BMC Infectious Diseases 17:695. doi: 10.1186/s12879017-2773-2

Tuaillon, E., Kania, D., Gordien, E., Van de Perre, P., and Dujols, P. (2018). Epidemiological data for hepatitis D in Africa. Lancet Glob Health 6, e33. doi: 10.1016/S2214-109X(17)30463-1
Tuaillon, E., Mondain, A.-M., Meroueh, F., Ottomani, L., Picot, M.-C., Nagot, N., et al. (2010). Dried blood spot for hepatitis C virus serology and molecular testing. Hepatology 51, 752-758. doi: 10.1002/hep. 23407

Tuaillon, E., Mondain, A.-M., Nagot, N., Ottomani, L., Kania, D., Nogue, E., et al. (2012). Comparison of serum HBsAg quantitation by four immunoassays, and relationships of HBsAg level with HBV replication and HBV genotypes. PLoS ONE 7:e32143. doi: 10.1371/journal.pone.0032143

Viljoen, J., Gampini, S., Danaviah, S., Valéa, D., Pillay, S., Kania, D., et al. (2010). Dried blood spot HIV-1 RNA quantification using open real-time systems in South Africa and Burkina Faso. J. Acquir. Immune Defic. Syndr. 55, 290-298. doi: 10.1097/QAI.0b013e3181edaaf5

Waters, L., Kambugu, A., Tibenderana, H., Meya, D., John, L., Mandalia, S., et al. (2007). Evaluation of filter paper transfer of whole-blood and plasma samples for quantifying HIV RNA in subjects on antiretroviral therapy in Uganda. J. Acquir. Immune Defic. Syndr. 46, 590-593. doi: 10.1097/qai. 0b013e318159d7f4

World Health Organization [WHO] (2014). Technical and operational considerations for implementing HIV viral load testing: interim technical update. Geneva: WHO.

World Health Organization [WHO] (2016). Combating hepatitis B and C to reach elimination by 2030. Geneva: World Health Organization.

World Health Organization [WHO] (2017). Guidelines on hepatitis B and C testing. Geneva: WHO.

World Health Organization [WHO] (2018). Public reports of World Health Organization prequalified IVDs: Abbott RealTime HIV-1 (m2000sp). PQDx 0145-027-00. 2018, version 8.0. Geneva: WHO.

World Health Organization [WHO] (2019). Performance evaluation acceptance criteria for HBsAg In vitro diagnostics in the context of WHO prequalification*. Available at: http://www.who.int/diagnostics_laboratory/evaluations/hepb/ 161125_who_performance_criteria_hbsag_ivd.pdf (accessed Febuary 27, 2020).

Zida, S., Tuaillon, E., Barro, M., Kwimatouo Lekpa Franchard, A., Kagoné, T., Nacro, B., et al. (2016). Estimation of HIV-1 DNA Level Interfering with Reliability of HIV-1 RNA Quantification Performed on Dried Blood Spots Collected from Successfully Treated Patients. J. Clin. Microbiol. 54, 1641-1643. doi: 10.1128/JCM.03372-15

Conflict of Interest: The authors declare that the research was conducted in the absence of any commercial or financial relationships that could be construed as a potential conflict of interest.

Copyright (C) 2020 Tuaillon, Kania, Pisoni, Bollore, Taieb, Ontsira Ngoyi, Schaub, Plantier, Makinson and Van de Perre. This is an open-access article distributed under the terms of the Creative Commons Attribution License (CC BY). The use, distribution or reproduction in other forums is permitted, provided the original author(s) and the copyright owner(s) are credited and that the original publication in this journal is cited, in accordance with accepted academic practice. No use, distribution or reproduction is permitted which does not comply with these terms. 